
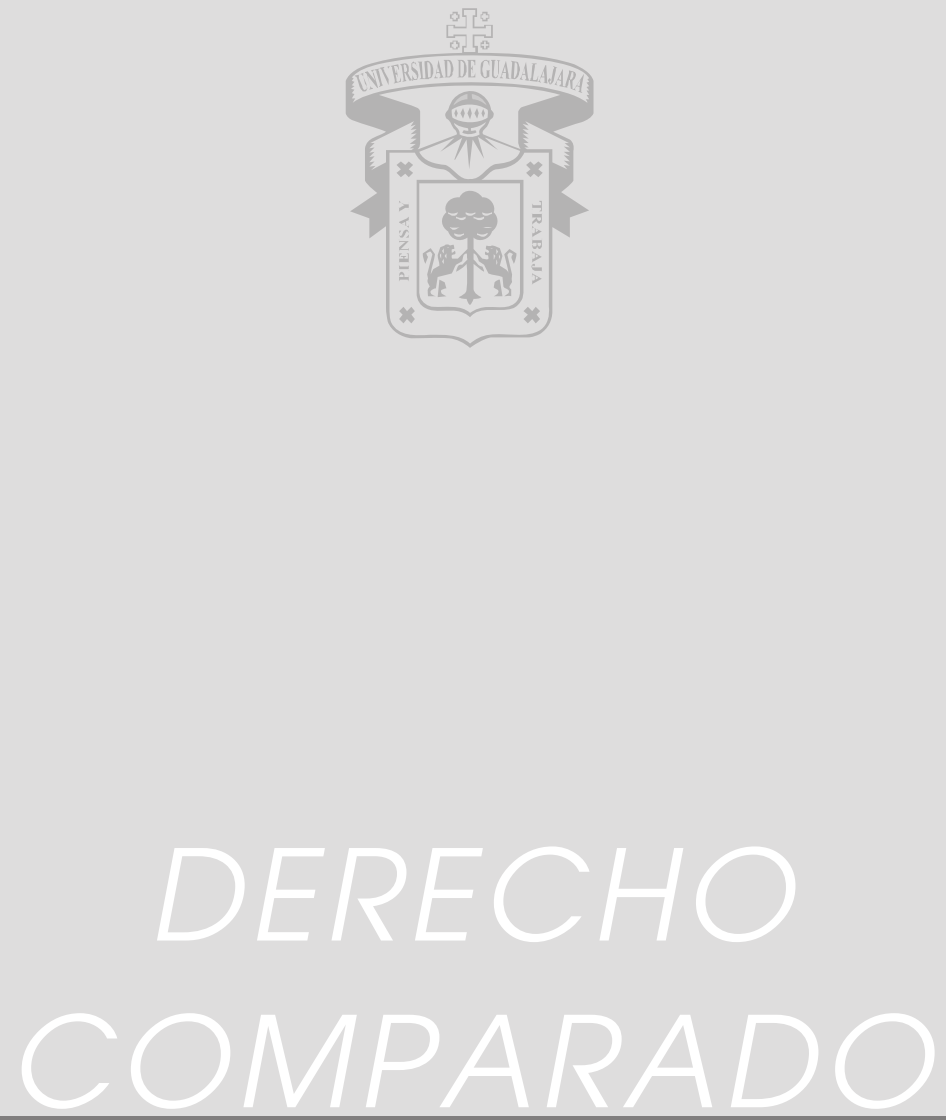


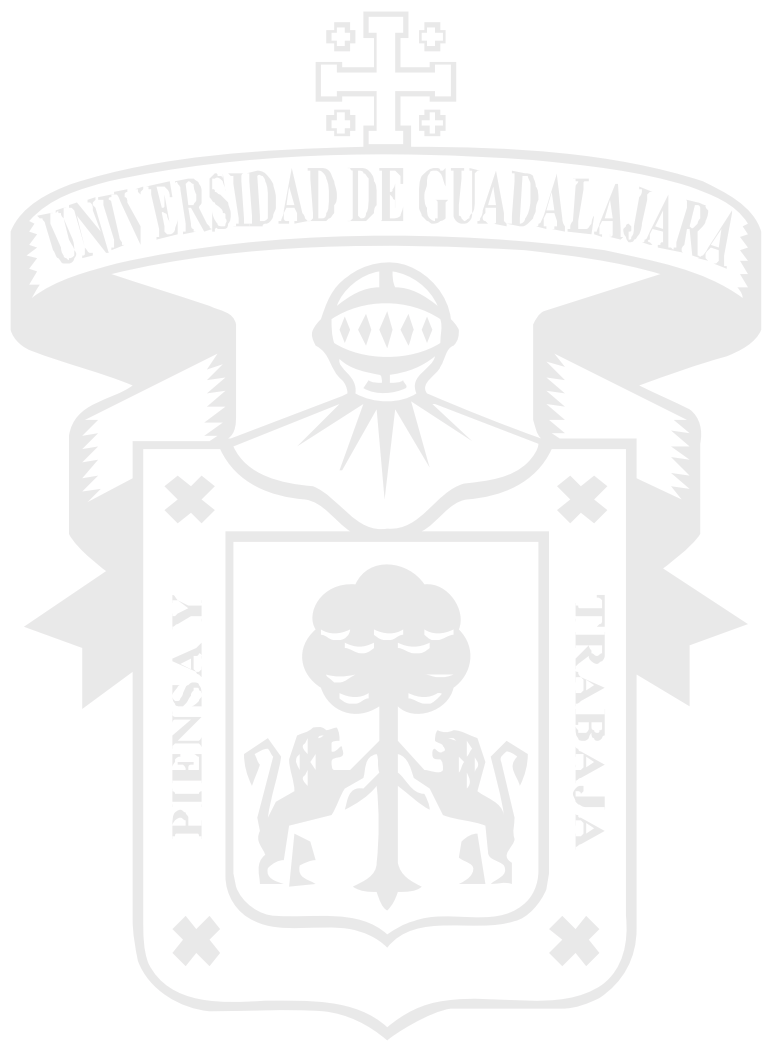




\section{La construcción de una magistratura activa y comprometida. \\ "Cambio de paradigma en el modelo de juez"}

El reciente Código Civil y Comercial de la Nación Argentina ${ }^{1}$, ha sido diseñado a partir de las realidades de nuestra sociedad, pretendiendo dar respuestas a la complejidad de la urdimbre colectiva. En efecto, es un cuerpo normativo que constitucionaliza el derecho privado, a fin de armonizar integralmente el sistema jurídico argentino.

Por el caso, las primeras disposiciones (arts. 1, 2 y 3), pertenecientes al Título Preliminar, Capitulo $1^{\circ}$, a más de ser preceptos destinados al juez de los "casos" y "asuntos", se erige un relevante significado sobre la estructura constitucional y convencional, que constituyen los instrumentos cardinales para la interpretación y aplicación del mismo, desde una perspectiva sistémica y armónica².

La postrema codificación ha unificado instituciones civiles y comerciales, bajo el estricto amparo de principios (optimizadores) que impregnan los tratados de Derechos Humanos. De ello, se desprende la preferente tutela de la dignidad, privacidad, igualdad de género, vulnerables y libertad individual, etc., a fin de que cada uno pueda gobernar su vida, como lo desea. En términos generales, es un código comprometido con la concepción humanista del derecho, con normas reservadas a salvaguardar los derechos personalísimos, procurando superar el modelo tradicional de los siglos anteriores.

${ }^{1}$ Cuya vigencia comenzó a regir a partir del 1 de agosto de 2015.

${ }^{2}$ Art. $1^{\circ}$ : Fuentes y aplicación. Los casos que este Código rige deben ser resueltos según las leyes que resulten aplicables, conforme con la Constitución Nacional y los tratados de derechos humanos en los que la República sea parte. A tal efecto, se tendrá en cuenta la finalidad de la norma. Los usos, prácticas y costumbres son vinculantes cuando las leyes o los interesados se refieren a ellos o en situaciones no regladas legalmente, siempre que no sean contrarios a derecho y Art. $2^{\circ}$ :Interpretación. La ley debe ser interpretada teniendo en cuenta sus palabras, sus finalidades, las leyes análogas, las disposiciones que surgen de los tratados sobre derechos humanos, los principios y los valores jurídicos, de modo coherente con todo el ordenamiento.

*Universidad de Salamanca, España.pablosanchezlatorre@gmail.com 
En suma, es un código distinto, con renovados paradigmas disímiles y para una sociedad también diversa. Entendemos que el vértice del cambio paradigmático, estriba en la teleología preceptiva, que demanda un nuevo modelo del sujeto "juez", sellando como vital, al estándar de la razonabilidad ${ }^{3}$ en la fundamentación de la decisión judicial.

A este flamante estándar de juez, ya no le bastará el método de la subsunción (deductiva) del caso a una norma (modelo tradicional - juez espectador), sino que debe analizar el sistema jurídico cabalmente, y no, mediante disposiciones aisladas, porque el codificador ha incorporado expresamente una matriz dinámica y normativista a los "principios" y "valores" de una sociedad determinada.

Entonces, se exhorta el perfil de un magistrado activo, razonable, prudente y con un prístino compromiso ético del eficaz ejercicio judicial, y no especulativo. Además, que sea un hombre imbuido en problemáticas que afectan al colectivo social, alejándose de los formalismos vetustos de las sentencias dogmáticas, asumiendo la potencialidad que le confiere el ordenamiento sistémico, con meridiana responsabilidad, meritando las posibilidades y consecuencias (variables económicas, externalidades sociales, ambientales, eficiencia, justicia, equidad, etc.) que ciertamente provocará el dictado de la sentencia, a fin de que éstas, sean posibles y claras.

En otras palabras, debe tomar medidas razonables, para asegurar la eficacia de la decisión. Es imprescindibleque el juzgador adopte un talante consciente, erradicando argumentaciones aparentes. Por el contrario, deberá (operador deóntico) partir desde una interpretación sistémica de todo el ordenamiento nacional y supranacional, anclando en la concepción principialista, axiológica y humanista.

Para los casos difíciles, el juez debe estar capacitado para "ponderar", los derechos que colisionan en la zona de conflicto, lo que implica un mayor despliegue de argumentación en la decisión. Ello, por cuanto debe abandonarse

\footnotetext{
${ }^{3}$ Art. 3: Deber de resolver. El juez debe resolver los asuntos que sean sometidos a su jurisdicción mediante una decisión razonablemente fundada.
} 
la práctica de que el Código Civil, ocupaba la centralidad del razonamiento y solución del caso, en razón, que ésta configuración ha sido sustituido por la constitucionalización del Derecho Civil, y el orden codificado, por el "sistema de Derecho Civil", que comprende la norma codificada, como a otras de los microsistemas legales. En consecuencia, la exigibilidad de elaborar un juicio de ponderación se pone en juego al momento de justipreciar derechos, principios o valores en tensión de sistema y microsistemas, de los cuales, el Código Civil y Comercial, forma parte.

Sobre el andarivel de las atribuciones y deberes del juez, puede o debe, según el caso, disponer, a modo enunciativo sobre los siguientes supuestos: El derecho a la coparentalidad o acceso de los niños a ambos padres, en caso de cese de la unión convivencial o matrimonial de la pareja parental fijando el régimen oficiosamente (arts. 650,651, 656); sobre la identidad personal, admitiendo que niños con edad y madurez suficiente para comprender el alcance de averiguar sobre la propia historia accedan a saber su origen (art. 596), incluso a saber acerca del donante en supuestos de técnicas de reproducción (arts. 563 y 564); morigerar intereses pactados (art. 771); fijar el precio de la cosa vendida en el contrato de compraventa; ejercer el control de las cláusulas abusivas en los contratos de adhesión y de consumo (arts. 989 y 1122); moderar condenas pecuniarias en la acción preventiva (art. 1714 y 1715); decidir sobre la distribución de la carga de la prueba (art. 1735); atenuar la responsabilidad (art. 1742); fijar el monto de la indemnización ante un daño a la intimidad (art. 1770); proceder al análisis de los títulos presentados en las acciones posesorias (art. 2270); ordenar la sustitución del derecho de retención por una garantía (art. 2589), etc.

En su mérito, las nuevas reglas de inteligencia judicial, dispuestas por el Código Civil y Comercial, se infiere un próvido empoderamiento y confianza, que incrementa los espacios de discrecionalidad, con amplios poderes y deberes, a este nuevo plano de juez. Quien deberá evitar decisiones contradictorias, y asumir la responsabilidad de contribuir a la seguridad jurídica, por cuanto, sus decisiones, deben propender hacia una sana predictibilidad. 
Indudablemente, la actividad jurisdiccional necesita de jueces probos, éticos, que utilicen el proceso para arribar a la justicia del caso, con una razonable aplicación del derecho (ley, principios, valores, usos, costumbres, sentido común), que sean creativos en su utilización, y argumenten incluso en contra de la regla escrita, en función de valores superiores, de ser el caso. Además, al justiciable se le deben brindar respuestas razonablemente fundadas, en un lenguaje comprensible y accesible.

Po su parte, Perelman sostiene que la razonabilidad es "una síntesis que combina la preocupación de la seguridad jurídica con la equidad, la búsqueda del bien común con la eficacia en la realización de los fines admitidos", de donde más que al legislador, es al juez al que se confiará la realización de esa síntesis. En esta línea, la Comisión Redactora expresa: "razonablemente fundada" es una expresión que "se ajusta a lo que surge de la doctrina de la arbitrariedad de sentencias".

El condicionante requisito de razonabilidad, es "un estándar de control de la decisión judicial" lo que palmariamente significa que no constituyen como tales, aquellas resoluciones que arriban a resultados disvaliosos o antifuncionales. Bajo esta sensatez, se obtiene una consecuencia no menor, si lo meritorio es extirpar la arbitrariedad de las sentencias, efectivamente, lo razonable, de acuerdo con el alcance asignado a los principios y valores prescriptos en el art. $2^{\circ}$, se concluye que la decisión razonablemente fundada, no es otra que una decisión moral.

El juez del nuevo código civil y comercial, deberá ejercer el protagonismo que le ha sido generosamente confiado, para estar al servicio de la sociedad y de los justiciables, apoyándose en un constante estudio de la teoría general del derecho y los tratados de derecho humanos, que es dónde se advierten las mayores debilidades. 